\title{
Correction to: Microdialysis in Postoperative Monitoring of Gastrointestinal Organ Viability: A Systematic Review
}

\author{
Jonas Emil Sabroe $^{1} \cdot$ Niels Qvist $^{1} \cdot$ Mark Bremholm Ellebæk $^{1}$
}

Published online: 3 April 2019

(C) Société Internationale de Chirurgie 2019

Correction to: World J Surg (2019) 43:944-954

https://doi.org/10.1007/s00268-018-4860-y

In the original article, most of the reference numbers in the first column in Table 1 are off by one reference. Following is the corrected table:

The original article can be found online at https://doi.org/10.1007/ s00268-018-4860-y.

Niels Qvist

famqvist@dadlnet.dk; niels.qvist@rsyd.dk

1 Department of Surgery, Odense University Hospital, J.B.

Winsløws Vej 4, 5000 Odense, Denmark 


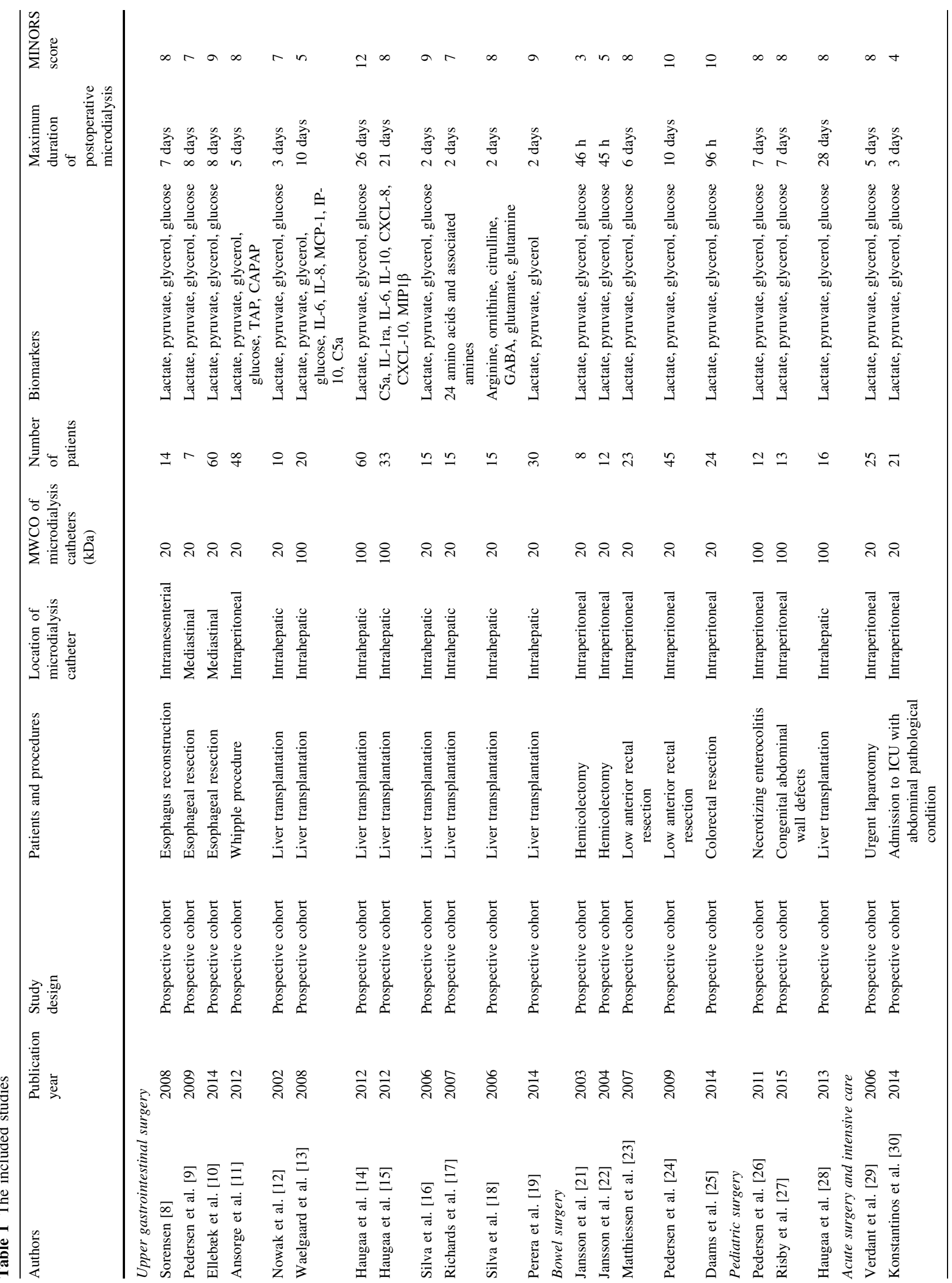




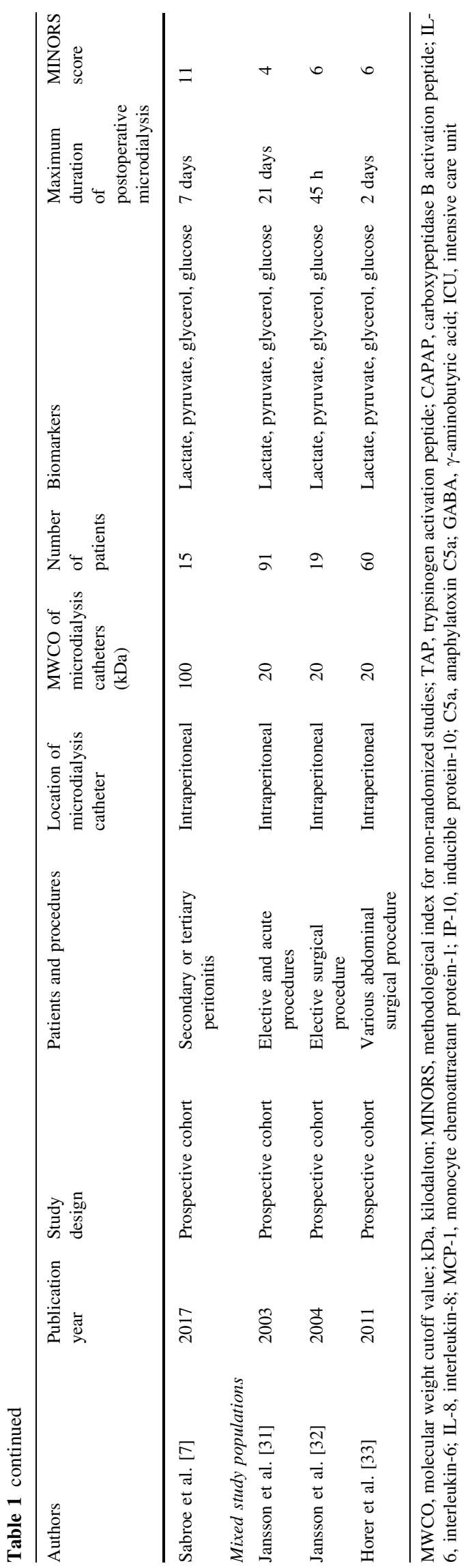

Publisher's Note Springer Nature remains neutral with regard to jurisdictional claims in published maps and institutional affiliations. 